\title{
Characterization of Tensile Properties and Fracture Toughness of Equal Channel Angular Pressed Al-Zn Alloy
}

Mohan kumar S ( $\nabla$ mohankumars.ase@gmail.com )

Department of Mechanical Engineering, Amrita School of Engineering

H K Govindaraju

BMS Institute of Technology and Management

M D Kiran

BMS Institute of Technology and Management

\section{Research Article}

Keywords: mechanical properties, Al-Zn alloy, ECAP, ASTM E399 standard, scanning electron microscope (SEM)

Posted Date: June 3rd, 2021

DOI: https://doi.org/10.21203/rs.3.rs-580135/v1

License: (c) (i) This work is licensed under a Creative Commons Attribution 4.0 International License. Read Full License 


\section{Abstract}

Influence of Equal channel angular pressing on mechanical properties and Fracture toughness of Al-Zn alloy were studied in present investigation. Samples are successfully processed using the ECAP technique for up to a four passes by using route A. Al-Zn alloys were heated to a solid solution treatment temperature at $550^{\circ} \mathrm{C}$ for 2 hours prior to ECAP, this treatment introduces the precipitates which were capable of obstructing motions of dislocation and improves the refinement of the grain during ECAP process Finally, artificial ageing was performed at a temperature of $190^{\circ} \mathrm{C}$ for $0-20$ hours with an interval of $2 \mathrm{hr}$ and specimens are cooledat room temperature with natural air.Fracture toughness was found experimentally for ECAP processed samples using SE (B) specimens according to ASTM E399 standard.Study revealed the enhancement in mechanical properties such as yield strength, ultimate strength and microhardness after four passes by route A technique.The improvement in the fracture toughness properties of artificially aged ECAP samples can also be due to dislocation strengthening, grain boundary strengthening, and the creation of much finer UFG grains, according to the results. Despite the increased tensile strength after ECAP, the ductility behaviour has decreased due to the precipitation of GP zones and dispersion of $\eta, \dot{\eta}, T$ and $E$ within the Aluminium matrix Furthermore, scanning electron microscope (SEM) micrographs revealed that ductile fracture with large dimples occurred in the artificial aged samples after the ECAP procedure.

\section{Introduction}

Aluminum \& its alloy are characterized by a relatively low density $2.7 \mathrm{gm} / \mathrm{cm}^{3}$ as compared to steel andit offers resistance to corrosion in some common environments including the ambient temperatures. Aluminum alloys typically have an elastic modulus of around $70 \mathrm{GPa}$, which is about one third of the elastic modulus of steel. Although aluminum alloys have higher tensile strengths than commonly used steels. When designing new products, the design choices are often governed by the special manufacturing technologies Extrusions are particularly important in this regard. Aluminum alloys often with copper, zinc, manganese, silicon, or magnesium are much lighter and more corrosion resistant than plain carbon steel, but not quite as corrosion resistant as pure aluminium [1]. Aluminum alloy Heat Treatment process involving heating and cooling of a metal or alloy in a solid state to obtain certain desirable properties such as homogeneous structure, better machinability, improved ductility etc [2]. Alloy 7075 is a high and is available in wide variety of product forms. It is also available in several types of tempers, i.e., T6, T73 \& T76 type. The T6 temper has the highest strength but lowest toughness and resistance to stress-corrosion cracking [3]. Since toughness decreases with a decrease in temperature, the T6 temper is not generally recommended for cryogenic applications.

Several factors influence the mechanical properties of all crystalline materials, but the average grain size plays a critical and dominant role.To reduce the grain size of a material using metal-working techniques, a high strain must be imposed in order to introduce a high density of dislocations, which are then rearranged to form an array of grain boundaries [4].In reality, due to the constraints of traditional metalworking techniques in terms of total imposed strains, focus has shifted to techniques focused on extreme 
plastic deformation (SPD) [5].In SPD operation, equal channel angular pressing (ECAP) applies substantial plastic strain to materials without reducing their cross-sectional area.Though ECAP increases strength as dislocation density increases, the elongation to failure associated with dislocation movement decreases after the first pass. As a result, the core mechanical properties of materials, strength and ductility, usually have conflicting characteristics. The specimen is pressed into a die made up of two intersecting channels with the same cross-sections in the ECAP method [6]. It has been demonstrated that die channel angle and channel length have a significant impact on the magnitude of plastic strain in deformed samples.Amid the four common routes $A, C, B_{A}$ and $B_{C}$ for performing ECAP process, $A$ and $B_{C}$, have been used more frequently than the others. Unlike route $A$, where the samples are pressed in consecutive passes without being rotated, route BC rotates the specimens by $90^{\circ}$ in the same direction at each pass.

Vinogradov and Hashimoto investigated the fatigue behaviour of severely deformed metals [7].The study found that grain boundaries have a significant impact on the materials' of low and high cycle fatigue behaviours. Because of the significant decrease in ductility during the process, SPD materials have shorter low cycle fatigue (LCF) exists than coarse-grained solids.A optimal combination of strength and ductility, on the other hand, leads to stronger fatigue properties.Several studies on the impact of crack plane orientation on the fatigue and fracture behaviour of UFG materials were conducted. Hohenwarter and Pippan [9] investigated the fracture toughness of ECAP-deformed iron as well as the influence of crack plane orientation on fracture toughness. They assessed fracture toughness properties in different orientations. The crack plane orientation has an important influence on fracture toughness, according to their findings.In several investigations, elastic-plastic fracture mechanics was used to evaluate the fracture toughness of UFG materials, but in others, material and geometry permits linear elastic fracture mechanics to be used (LEFM) [10]. Besides, using molecular dynamics simulation, the fracture toughness of nanocrystalline a-Fe is theoretically investigated, and it is shown that this parameter increases with decreasing grain size [11]. However, several research in the literature have found that grain refining reduces fracture toughness. In contrast, even though SPD reduces fracture toughness, grain refinement increases the result of fracture toughness and yield strength, which can be considered an improvement [12].

In the present work, Fracture Toughness of Al-Zn alloy subjected to a solid solution treatment and artificial aged samples are processed by ECAP by route A technique was investigated experimentally with a die channel and corner angles of $90^{\circ}$ and $20^{\circ}$ respectively. Mechanical properties such as Yield strength, Tensile strength and microhardness were found and presented. To evaluate the behaviours, Furthermore, SEM images were taken from the fracture surfaces of ECAP samples to compare the grain size and fracture mechanisms of specimens.EDAX analysis is carried out to know the chemical compositions of the Solid solution and artificial aged samples subjected to ECAP process

\section{Experimental Procedure And Material}


Liquid metallurgy technique is employed for processing of ingots into an experimental specimens. Al-Zn alloys used in present study had following major alloying compositions in \%wt of $5.9 \mathrm{Zn}, 2.8 \mathrm{Mg}, 1.8 \mathrm{Cu}$, $0.56 \mathrm{Fe}, 0.45 \mathrm{Mn}, 0.2 \mathrm{Cr}$ and balance Aluminum. Casted Al-Zn alloy rods were machined to a dimension of $15 \mathrm{~mm}$ of diameter and $100 \mathrm{~mm}$ length, later the specimens were first treated at $550^{\circ} \mathrm{C}$ for 1 hour before being quenched with water to create a super saturated solid solution. Solid solution treated specimens are pressedthrough an ECAP solid die having a channel angle of $\varphi=90^{\circ}$ and an outer curvature angle of $\Psi=20^{\circ}$ shown in schematic Fig. 1(a). Billets were pressed at a temperature of $300^{\circ} \mathrm{C}$ in order to avoid the crack by following route $A$ the billet is pressed in the same sense without rotation of specimen as shown in Fig. 1(b) and processed for about 4 passes.ECAP processing was carried out at a $1 \mathrm{~mm} \mathrm{~s}^{-1}$ pressing speed with MoS2 as a lubricant to reduce frictional effects at the die walls [13]. These pressed specimens were then exposed to artificial aging at $190^{\circ} \mathrm{C}$ in Post-ECAP, with aging periods ranging from 0 to $20 \mathrm{Hrs}$ in an interval of $2 \mathrm{Hrs}$.

Hardness and tensile tests were performed to investigate the effect of ECAP on strength and ductility. The hardness of the material was determined in a plane parallel to the longitudinal axis and at various randomly selected locations by using Everone Vickers micro hardness tester. Tensile tests were carried out in compliance with ASTM E8 at room temperature [14].Optical SEM was used to examine the tensile and fracture test segmented specimens for microstructural analysis and fracture surface characterization.. The chemical compositions of Al-Zn alloy treated to solid solution and artificially aged samples subjected to the ECAP process are determined using EDAX analysis.

\section{Results And Discussion}

\section{Optical Microstructure Analysis}

Microstructural analysis of Solid solution and artificially aged Al-Zn alloy subjected to ECAP processing by route $A$ was studied systematically. Figure $2(b)$ revealed an elongated dislocation cell structure with a few platelet precipitates of $120 \mathrm{~nm}$ and various fine spherical precipitates, including several GP zones as well as $\eta$ and a few $\eta$ phases, after four passes of ECAP.Precipitates induced by the solid solution treatment prior to ECAP can speed up grain refinement and increase dislocation density by pinning dislocations [15]. Figure 2 shows standard micrographs of the Al-Zn alloy after post-ECAP heat treatments.The microstructure sample has nearly equiaxed grains that developed from the elongated dislocation cell structure after ECAP processing for 4 passes, as shown in Fig. 2(d).Since the elongated boundaries are not well-defined after 18 hour of artificial aged at $550^{\circ} \mathrm{C}$ sample, it is clear that the evolution is incomplete. In addition, there are several dislocations and dislocation tangles seen in Fig. 2. (c). Figure 2(c) shows that the microstructure is well-defined, with relatively equiaxed grains with an average size of $170 \mathrm{~nm}$ grains after increasing the holding time at $190^{\circ} \mathrm{C}$ to $16 \mathrm{hr}$.

Energy-dispersive X-ray spectroscopy (EDS, EDX, EDXS or XEDS), sometimes called energy dispersive Xray analysis (EDXA) or energy dispersive X-ray micro analysis (EDXMA), is an analytical technique used 
for the elemental analysis or chemical characterization of a sample. Its characterization capabilities are due in large part to the fundamental principle that each element has a unique atomic structure. The microstructure and EDS spectra of eutectic phases of Al-Zn alloy subjected to Solid Solution treatment are shown in Fig. 3. It can be observed thateutectic Al-Zn alloy were mainly composed of laminar structures and massive structures. The EDS analysis result shows that the stoichiometries of the lamellar eutectic phase are $81.13 \% \mathrm{Al}, 5.67 \% \mathrm{Zn}, 2.5 \% \mathrm{Mg}$, and $1.4 \% \mathrm{Cu}$ (molar fraction), as shown in Fig. 3, which are similar to the stoichiometries of $\mathrm{Mg}(\mathrm{Zn}, \mathrm{Cu}, \mathrm{Al})_{2}$ phases. The morphology and size of the massive $\mathrm{Al}_{7} \mathrm{Cu}_{2} \mathrm{Fe}$ phases show no change during the solution treatment due to its high melting point. While the base alloy shows discontinuity in the arrangement of precipitates in the matrix and along the grain boundary, the alloy after solid solution treatment continuous presence of precipitates in the matrix and along the grain boundary [20].

\section{Microhardness}

Table. 2 shows the micro hardness values of Al-Zn alloy evaluated up to four passes through route A technique with an artificial ageing duration ranging from 0 to 20 hours. It has been observed that the hardness increases significantly up to 14 hours of ageing. Enhancement of hardness is due to the precipitates fragmentation and a rise in dislocation density and grain refinement [16].The micro hardness has increased from $67 \mathrm{Hv}$ to $162 \mathrm{Hv}$ from 0 to $14 \mathrm{Hr}$ of aging duration ECAP processed samples in routeA which is the maximum among all aging duration.

\section{Tensile Properties}

Tensile tests were carried out in compliance with ASTM E8 at room temperaturespecimen dimension is shown in Fig. 4. Tensile properties were evaluated 0 to $20 \mathrm{Hr}$ duration of artificially aged samples up to four passes ECAP processed in route $A$ are shown in Table 2. Tensile strength continues to increase up to $16 \mathrm{Hr}$ of aged sample at four passes compared to all artificial aging duration samples. These results are in line with the trend observed in hardness (Table 2). Route ' $A$ ' $16 \mathrm{Hr}$ artificial aged sample shows UTS of $517 \mathrm{MPa}$ after four passes which is almost 1.7 times higher than the untreated aged ECAP sample. This is due the additional presence of intermediate semi-coherent precipitates and intermetallic compounds such as $\mathrm{CuAl}_{2}$ may cause heterogeneities in the plastic flow during stress application. Additional tension is required in this method to shift the dislocation, which eventually results in an increase in strength [17].There was no definite trend in the decreased \% of elongation of heat treated and ECAP processed Al$\mathrm{Zn}$ alloy, but it was found to decrease with increasing ageing time. 
Table 2

Mechanical properties of Al-Zn alloy after ECAP.

\begin{tabular}{|lllll|}
\hline $\begin{array}{l}\text { Artificial aged } \\
\text { Condition, Hr }\end{array}$ & $\begin{array}{l}\text { Average } \\
\text { Microharndess, HV }\end{array}$ & $\begin{array}{l}\text { Ultimate Tensile } \\
\text { Strength, MPa }\end{array}$ & $\begin{array}{l}\text { Tensile Yield } \\
\text { Strength, MPa }\end{array}$ & $\begin{array}{l}\text { Elongation } \\
\%\end{array}$ \\
\hline 0 & 67 & 297 & 279 & 10.42 \\
\hline 2 & 87 & 345 & 289 & 10.67 \\
\hline 4 & 96 & 369 & 344 & 10.8 \\
\hline 8 & 105 & 440 & 427 & 10.91 \\
\hline 10 & 108 & 460 & 437 & 10.37 \\
\hline 12 & 122 & 497 & 480 & 8.8 \\
\hline 16 & 137 & 502 & 489 & 8.02 \\
\hline 18 & 162 & 509 & 494 & 7.7 \\
\hline 20 & 158 & 517 & 497 & 7.93 \\
\hline
\end{tabular}

\section{Fracture Toughness Test}

To determine the influence of grain size on Al-Zn alloy, fracture toughness test were performed on ECAPprocessed samples in accordance with ASTM-E399 standards by using Bend Specimen SE (B). The testing specimens were taken from the ECAP processed billets' and cuts from central region using a wire cutting machine to achieve a specific geometry of Bend Specimen SE (B) with the dimensions shown in Figure. 5.A sharp crack was created by using a very thin wire with a diameter of $0.25 \mathrm{~mm}$.Despite the fact that fatigue cracking was not carried out according to the standard, this study is still relevant since a comparative and qualitative analysis of the fracture performance of samples with similar geometry, material, and loading conditions was carried out.Constant loading rate of $0.05 \mathrm{~mm} / \mathrm{s}$ was used to conduct a test [18].

Following the measures outlined in the ASTM standard, the force-CMOD (crack mouth opening displacement) plot can be used to determine the specimen's maximum sustainable load $\mathrm{P}_{\max }$ and $\mathrm{P}_{Q}$ is the load at every point in the test record. As predicted because of the reduced ductility after ECAP, a linear relationship between force and CMOD was obtained for the processed samples. The force-CMOD curve for the artificial aged material was linearized according to the code. For linearization, a line with a slope of $5 \%$ less than the mother curve's initial linear portion is chosen. $P_{\max }$ denotes the intersection point of this line with the curve. Table 3 shows the results for $P_{\max }$, with low data scattering serving as a strong indicator from a statistical standpoint. 
Table 3

$P_{\max }$ values for different ageing conditions ECAP processed samples

\begin{tabular}{|ll|}
\hline Material Aged conditions, $\mathrm{Hr}$ & $\mathbf{P}_{\max }, \mathbf{k N}$ \\
\hline 0 & 0.685 \\
\hline 2 & 0.745 \\
\hline 4 & 0.812 \\
\hline 6 & 0.866 \\
\hline 8 & 1.049 \\
\hline 10 & 1.066 \\
\hline 12 & 1.158 \\
\hline 14 & 1.239 \\
\hline 16 & 1,278 \\
\hline 18 & 1.098 \\
\hline 20 & 1.053 \\
\hline
\end{tabular}

The fracture toughness of each sample, $\mathrm{K}_{\mathrm{IC}}$, can be calculated using the following equations, according to the ASTM-E399 standard:

$K_{I C}=\left(\frac{P_{Q} S}{B W^{\frac{3}{2}}}\right) f(a / W)-$ Equation 1

The maximum applied load, specimen thickness, specimen width, span length, and crack sizeare represented by $\mathrm{P}_{\max }, \mathrm{B}, \mathrm{W}, \mathrm{S}$, and a respectively.For all specimens, the crack grows straight in the direction of the crack front, indicating symmetry and a pure opening mode loading state. After the fracture test, the specimens that failed are shown in Fig. 5.

Equation 1 is used to assess the fracture toughness of each sample. The determined $\mathrm{P}_{\max }$ and fracture toughness are within the valid range as indicated by the standard testing norm, taking into account the material and geometry conditions. The fracture toughness values of ECAP processed Al-Zn alloy samples were shown in Figure. 6 . The fracture toughness of $2 \mathrm{hr}$ aged condition samples improves from 12.94 to $21.68 \mathrm{MPa} \sqrt{\mathrm{m}}$, as shown in this figure. This is attributable is due to longer ageing hours of Al-Zn alloy ultra-fine grain refinement in ECAP processed samples. After four passes, the fracture toughness of $16 \mathrm{hr}$ aged samples is 81 percent higher than that of $0 \mathrm{hr}$ aged samples.As indicated in our tests and in the literature, after a considerable reduction in ductility of material after $10 \mathrm{hr}$ of aged condition the ductility remains approximately constant for the higher duration aging samples of ECAP processed samples while strength increases considerably between $12 \mathrm{hr}$ to $18 \mathrm{hr}$ aged samples. 
In contrast, because of the higher grain boundary volume fraction, crack tip blunting and crack arrest play a much greater role in UFG materials' fracture resistance, resulting in increased fracture toughness. Furthermore, certain processes, such as grain boundary accommodation, grain boundary triple junction activity, grain nucleation, and grain rotation are intensifies, become more active as grain size decreases.Fracture toughness should improve after grain refinement because these mechanisms regulate the rate of plastic energy release at the nanoscale. Experiments on metallic materials have shown that after grain refining, the hardening area, such as the plastic zone, is widened.

\section{Fracture Morphology Study}

Fracture analysis of ECAP processed Al-Zn alloy for different ageing conditions was studied by taking photographs of fractured samples and high magnification micrographs were taken using SEM and are presented in Fig. 7. Photographs of fractured ECAP processed Al-Zn alloy samples shown in Fig. 7 depicts that cracks formed are not straight as seen in case of cast alloys. The cracks follow tortuous paths in most of the samples especially the one aged for longer ageing time durations. The formation of tortuous paths in these samples explains higher the fraction energy absorption capacity of these alloys is very high. Fine dimples and limited ductilefracture features are observed in Fig. 7 (a-f), which corresponds to the UFG ECAP-processed samples. This implies that, after the process, the number of dimples increased and the dimple size are reduced due to the grain refinement and work hardening. The shallower dimples are present in comparison with very deep holes in the annealed samples due to decrease in the ductility, which is attributed to the deformation in the UFG by the dislocation movements.

\section{Conclusions And Summary}

In summary, Al-Zn alloy is processed up to four passes of ECAP by route A by using a split die with a right angle channel with a combination of Solid solution and artificial aged condition heat treatment. The study is conducted to evaluate the effects of ECAP on the fracture behaviour and mechanical characterization of Al-Zn alloy.The implementation of ECAP technique for processing Al-Zn alloy not only increases its strength but also improves its fracture toughness, according to the current analysis.Although heat-treated Al-Zn alloys may have higher tensile strength and fracture toughness than those obtained in this study, this paper is significant because ECAP technique is a suitable with industrialization potential that requires further investigation.

Major Conclusions are listed below:

- After four ECAP passes, the average grain size of Al-Zn was reduced from $120 \mu \mathrm{m}$ to less than 200 $\mu \mathrm{m}$.

- Al-Zn alloy yield andultimate tensile strengths improve from 279 to $497 \mathrm{MPa}$ and 297 to $517 \mathrm{MPa}$, respectively, after four passes of ECAP and ageing treatment varies from $0 \mathrm{hr}$ to $16 \mathrm{hr}$. However, 
elongation to failure drops from 10.4 to 7.7 percent.

- For $14 \mathrm{hr}$ aged ECAP samples microhardness is higher of $162 \mathrm{Hv}$ compared to all aging durations.

- After the ECAP process, the fracture toughness of Al-Zn increases from 12 to $22 \mathrm{MPam}$. This is because of the higher grain boundary volume fraction, crack tip blunting and crack arrest play a much greater role in UFG materials' fracture resistance, resulting in increased fracture toughness.

\section{References}

1. S. Mohan Kumar, H.K. Govindaraju, "An Investigation of the effects of solution treatment on Mechanical Properties of Aluminum 7075 alloys", INTERNATIONAL JOURNAL OF SCIENTIFIC \& TECHNOLOGY RESEARCH VOLUME 9, ISSUE 03, MARCH 2020, ISSN 2277-8616

2. Mohan kumar. S and Govindaraju. H. K, "Preparation And Mechanical Characterization Of Al7075Silicon Nitride Mmc's", International Journal of Mechanical and Production Engineering Research and Development (IJMPERD), Vol. 8, Issue 4, Aug 2018, 575-584

3. S. Mohan Kumar, V. Ravi Kumar, M.E. Shashi Kumar, H.K. Govindaraju "Mechanical characterization and fracture toughness of electroplated cadmium coating of Al-Zn alloy", T6", AIP Conference Proceedings 1859, 020085, 2017; https://doi.org/10.1063/1.4990238

4. V.M. Segal, V.I. Reznikov, A.E. Drobyshevskiy, V.I. Kopylov, Plastic working of metals by simple shear (Russian translation). Russ. Metall.1, 1981, pp.99-105

5. Z.Valieva Ruslan, Terence G.Langdon, "Principles of equal-channel angular pressing as a processing tool for grain refinement”. Prog. Mater Sci. 51, Issue 7, 881-981 (September 2006)

6. J. Vaclav Sklenicka, M. Dvorak, Svoboda, Petr Kral and Marie Kvapilova (December 5th 2012). "Equal-Channel Angular Pressing and Creep in Ultrafine-Grained Aluminium and Its Alloys, Aluminium Alloys - New Trends in Fabrication and Applications", Zaki Ahmad, IntechOpen, DOI:10.5772/51242

7. A. Vinogradov, S. Hashimoto, "Fatigue of severely deformed metals", Adv. Eng Mater. 5 (5) (2003) $351-358$

8. S. Mohan Kumar, "Evaluation of Fracture Toughness and Mechanical Properties of Aluminum Alloy 7075, T6 with Nickel Coating", Procedia Engineering, vol 97, pp 178-185, 2014

9. A. Hohenwarter, R. Pippan," Fracture of ECAP-deformed iron and the role of extrinsic toughening mechanisms", Acta Mater. 61(8), 2973-2983 (2013)

10. A. HohenwarterR. Pippan, "Fracture toughness evaluation of ultrafine-grained nickel", Scripta Materialia, Volume 64, Issue 10, May 2011, Pages 982-985

11. A. Latapie, D. Farkas, "Molecular dynamics investigation of the fracture behavior of nanocrystalline a-Fe", Phys. Rev. B 69, 134110 - Published 21 April 2004

12. I.Sabirova Kolednika, R.Pippan, "Equal channel angular pressing of metal matrix composites: Effect on particle distribution and fracture toughness",Acta Materialia Volume, 53, Issue 18, October 2005, Pages 4919-4930 
13. S.M. Ghalehbandi, A. Fallahi-Arezodar, H. Hosseini-Toudeshky, Fatigue crack growth resistance of $7075 \mathrm{Al}$ alloy after equal channel angular pressing. Fatigue Fract Engng Mater Struct 00, 1-9 (2016)

14. S. Mohan Kumar, K.R. Ravikiran, H.K. Govindaraju, 2018. "Development of E-glass woven fabric/polyester resin polymer matrix composite and study of mechanical properties". Materials Today: Proceedings, 5(5), pp.13367-13374

15. G. Sha, Y.B. Wang, X.Z. Liao, Influence of equal-channel angular pressing on precipitation in an Al$\mathrm{Zn}-\mathrm{Mg}-\mathrm{Cu}$ alloy. Acta Mater. 57, 3123-3132 (2009)

16. A. Mohamed, Y.C. Afifi, Wang, "Mechanical properties of an Al-Zn-Mg alloy processed by ECAP and heat treatments", Journal of Alloys and Compounds 769 (2018)

17. A. Mohamed, Y.C. Afifi, Wang, Effect of heat treatments on the microstructures and tensile properties of an ultrafine-grained Al-Zn-Mg alloy processed by ECAP”. J. Alloy. Compd. 749, 567e574 (2018)

18. F.Djavanroodi, M.Ebrahimi, “Fatigue design factors for ECAPed materials",Materials Science and Engineering: AVolume 528, Issue 2, 15 December 2010, Pages 745-750

19. B. Hossein Darban, Mohammadi, Faramarz Djavanroodi, "Effect of equal channel angular pressing on fracture toughness of Al-7075". Eng. Fail. Anal. 65, 1-10 (2016)

20. P.-X. Zhang, Hong Yan, "Effect of T6 Heat Treatment on Microstructure and Hardness of Nanosized Al203 Reinforced 7075 Aluminum Matrix Composites",Metals 2019, 9, 44; doi:10.3390/met9010044

\section{Figures}
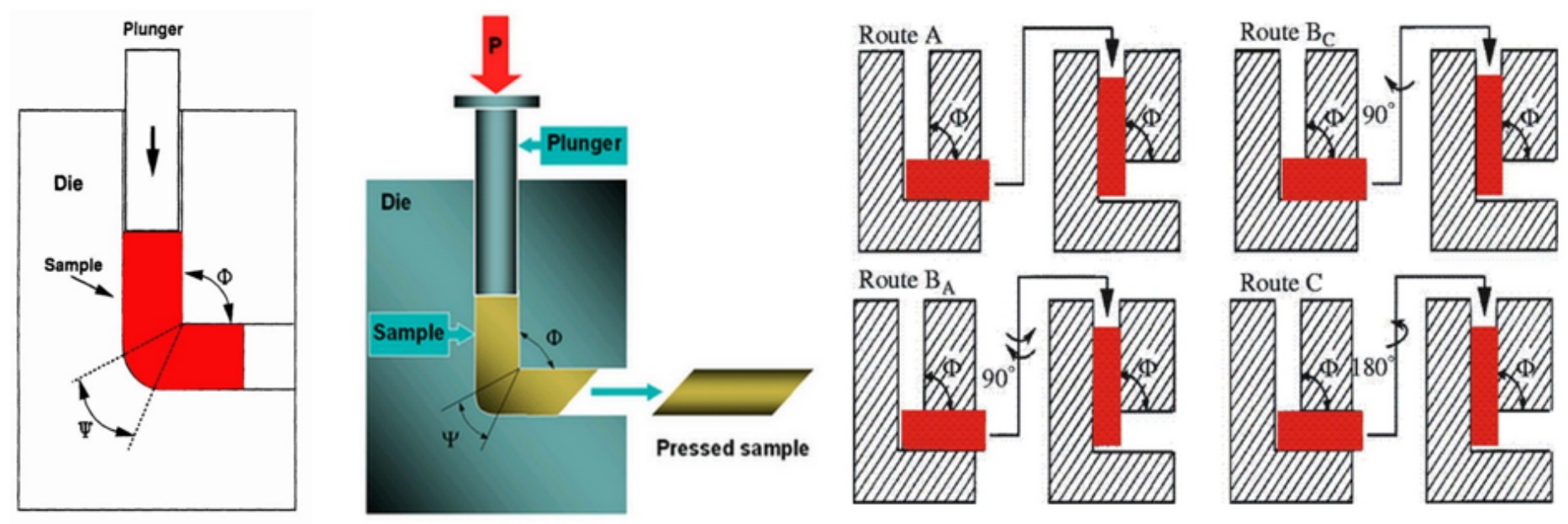

Figure 1

(a) ECAP Process Principle [1] (b) ECAP Processing Routes 


\section{a}

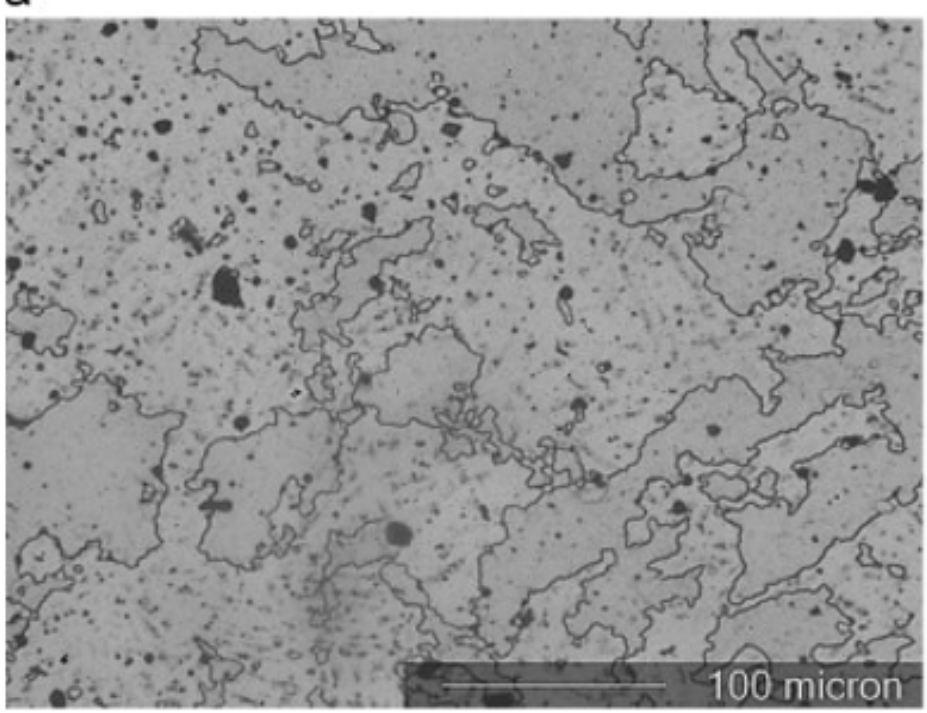

C

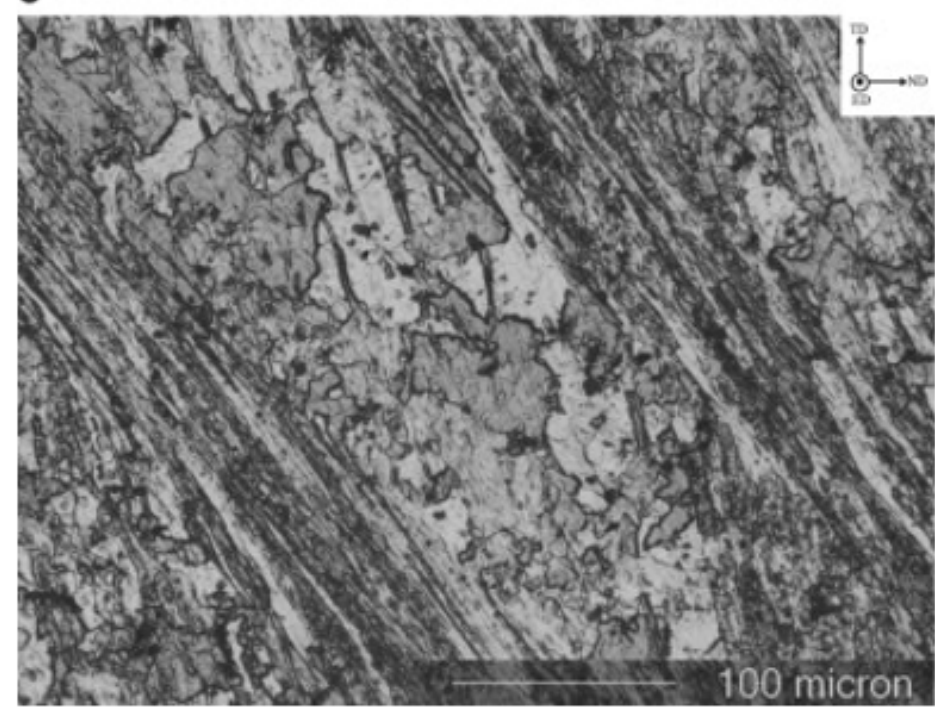

b

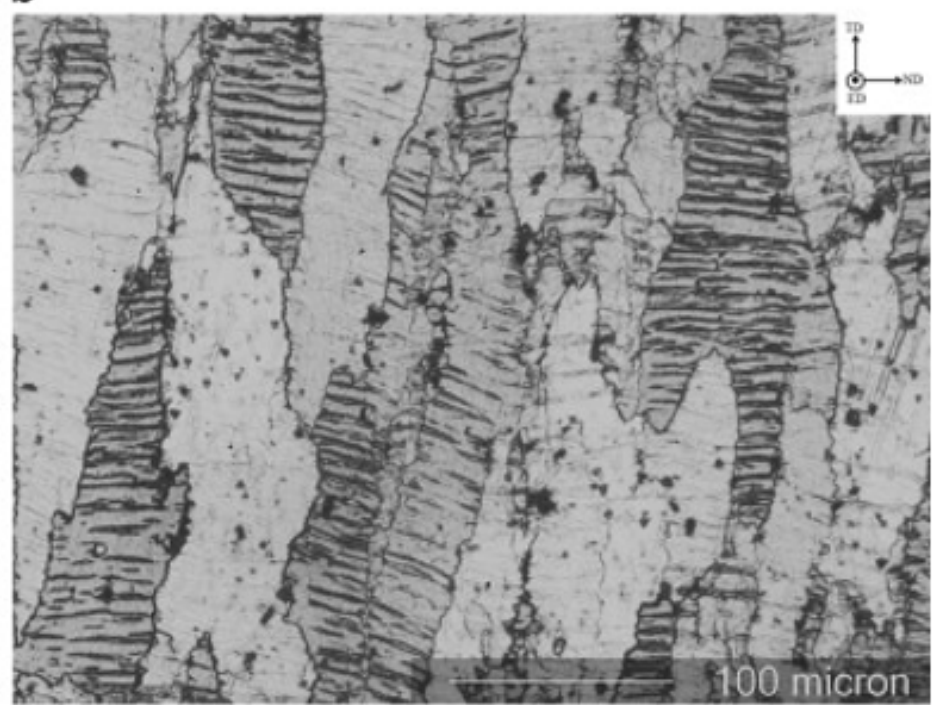

d

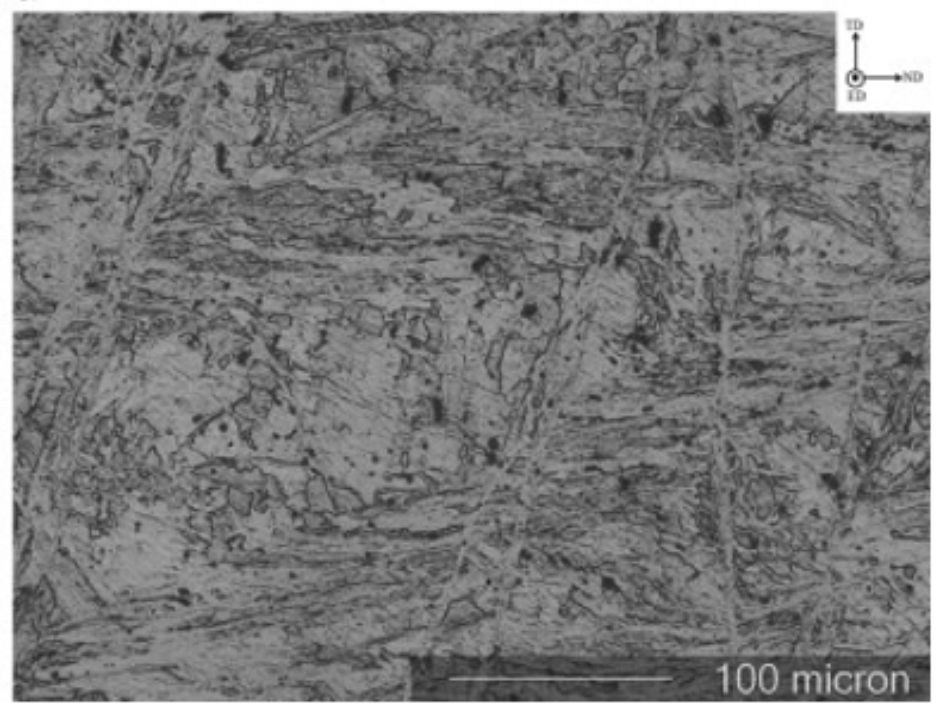

Figure 2

Optical micrographs of ECAP processed Al-Zn alloy at different ageing durations 


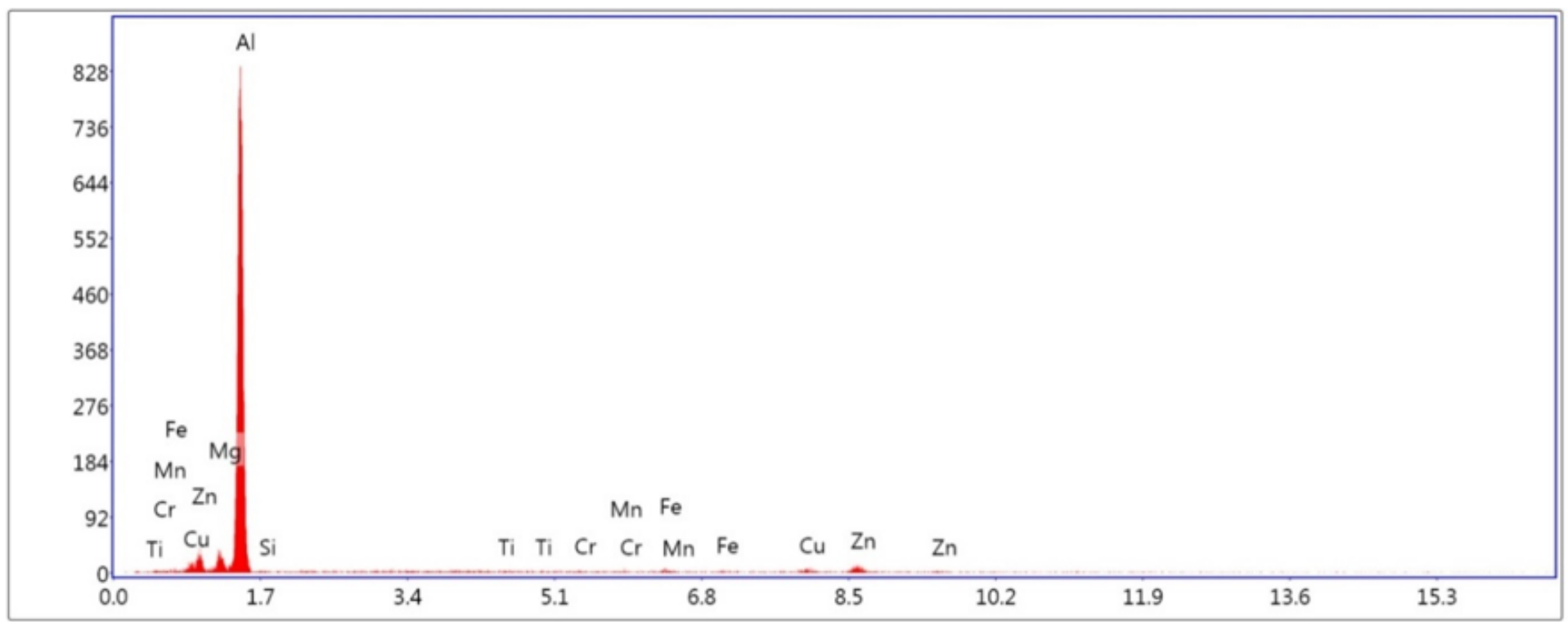

Lsec: $26.9 \quad 0$ Cnts $\quad 0.000 \mathrm{keV} \quad$ Det: Octane Pro Det

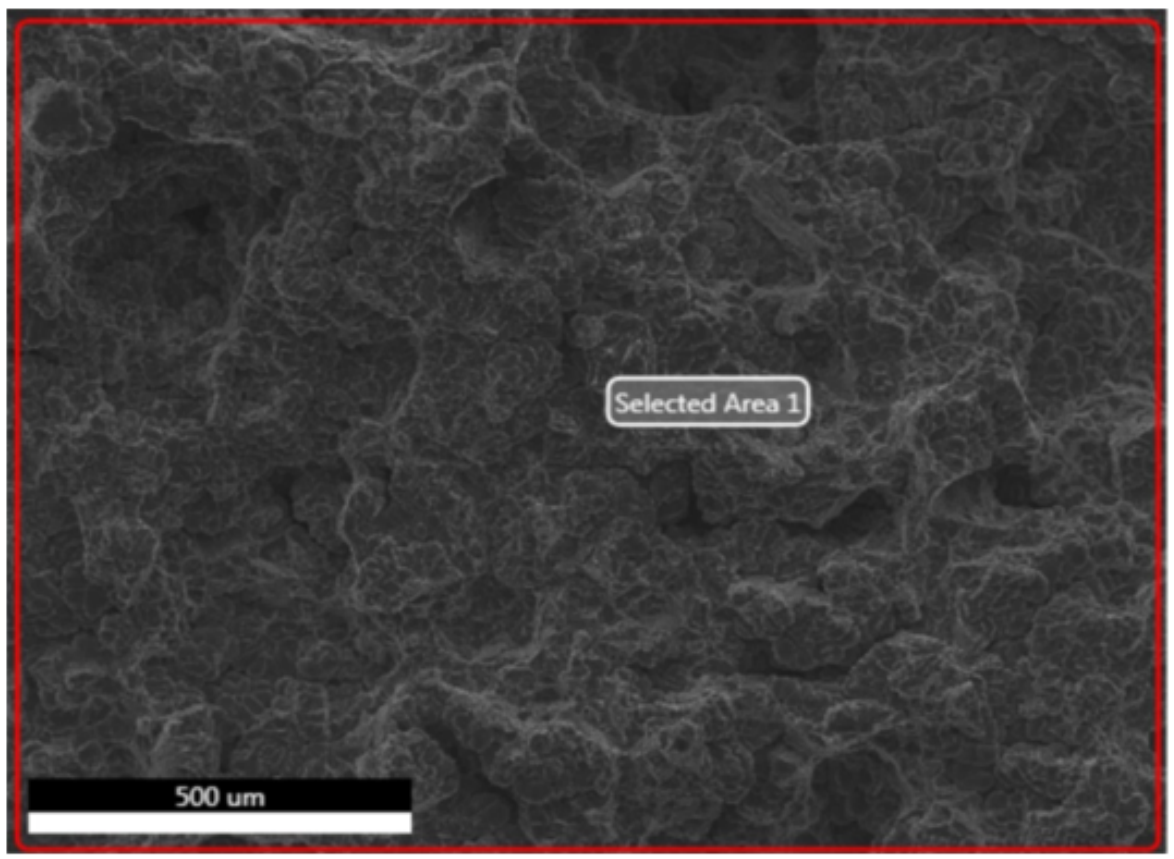

Figure 3

SEM image of Al-Zn alloy (a), EDAX patterns of selected area 


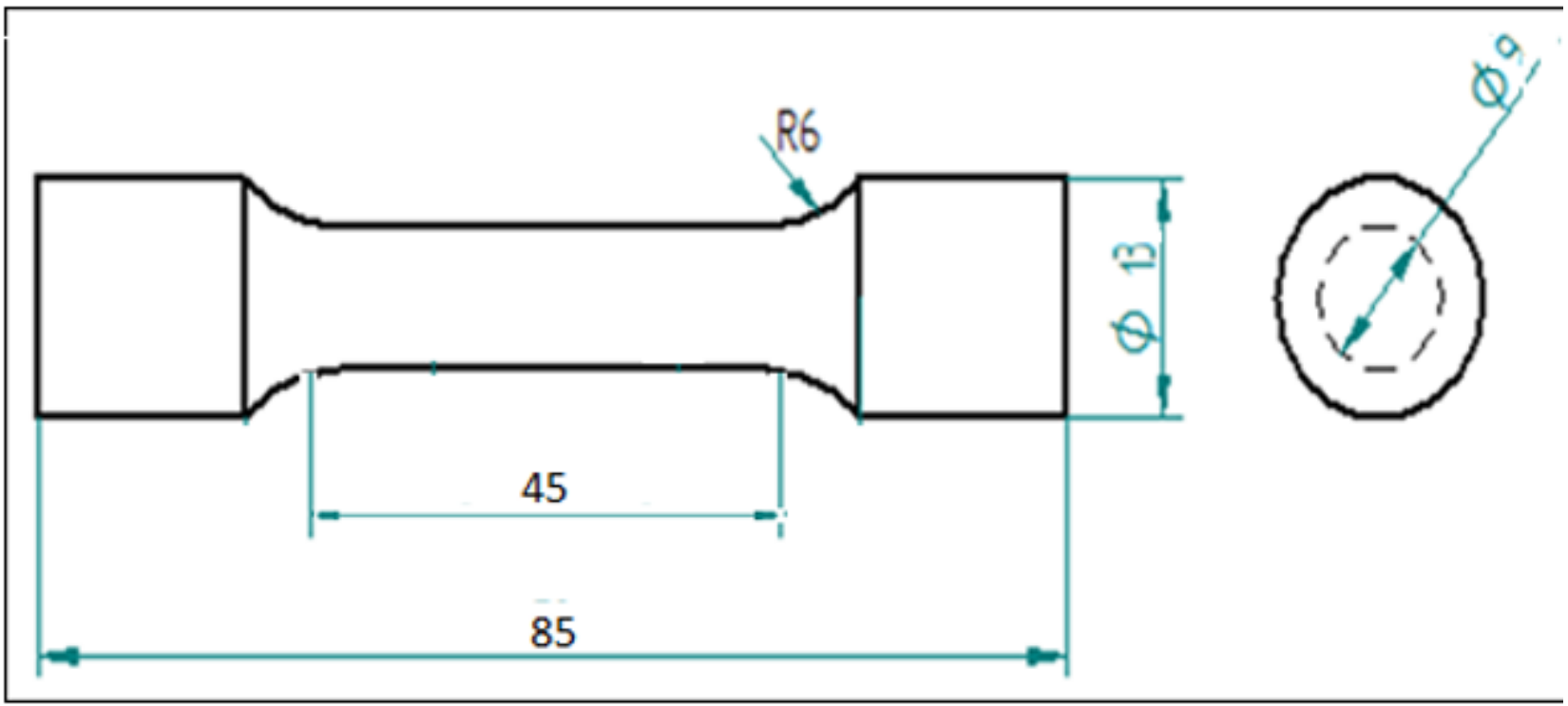

Figure 4

Dimensions of the Tensile test specimen as per ASTM E8.

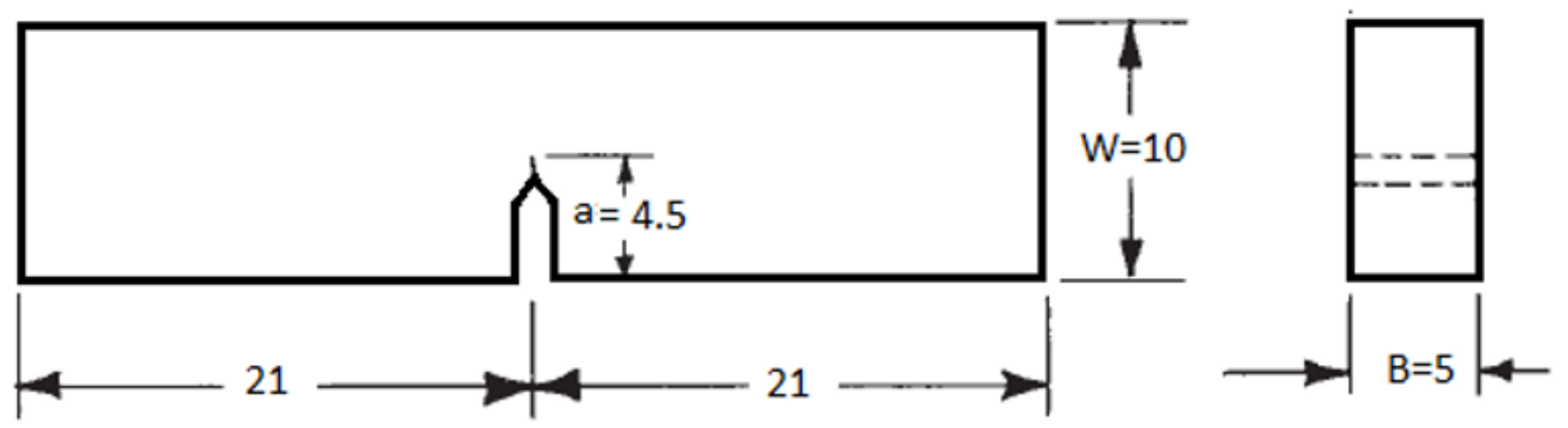

Figure 5

Dimensions of Bend Specimen SE (B)

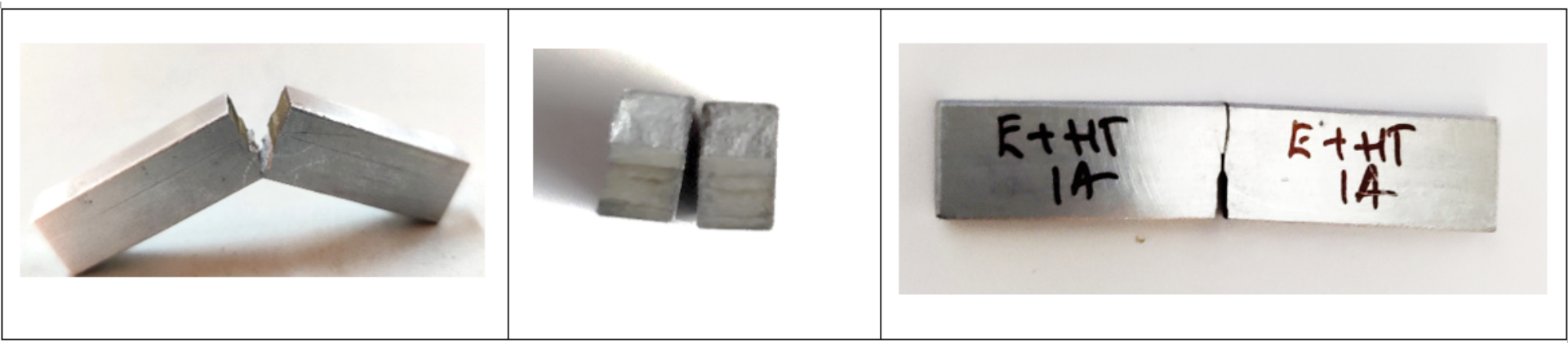

Figure 6

Specimen failed after Fracture Toughness Test 


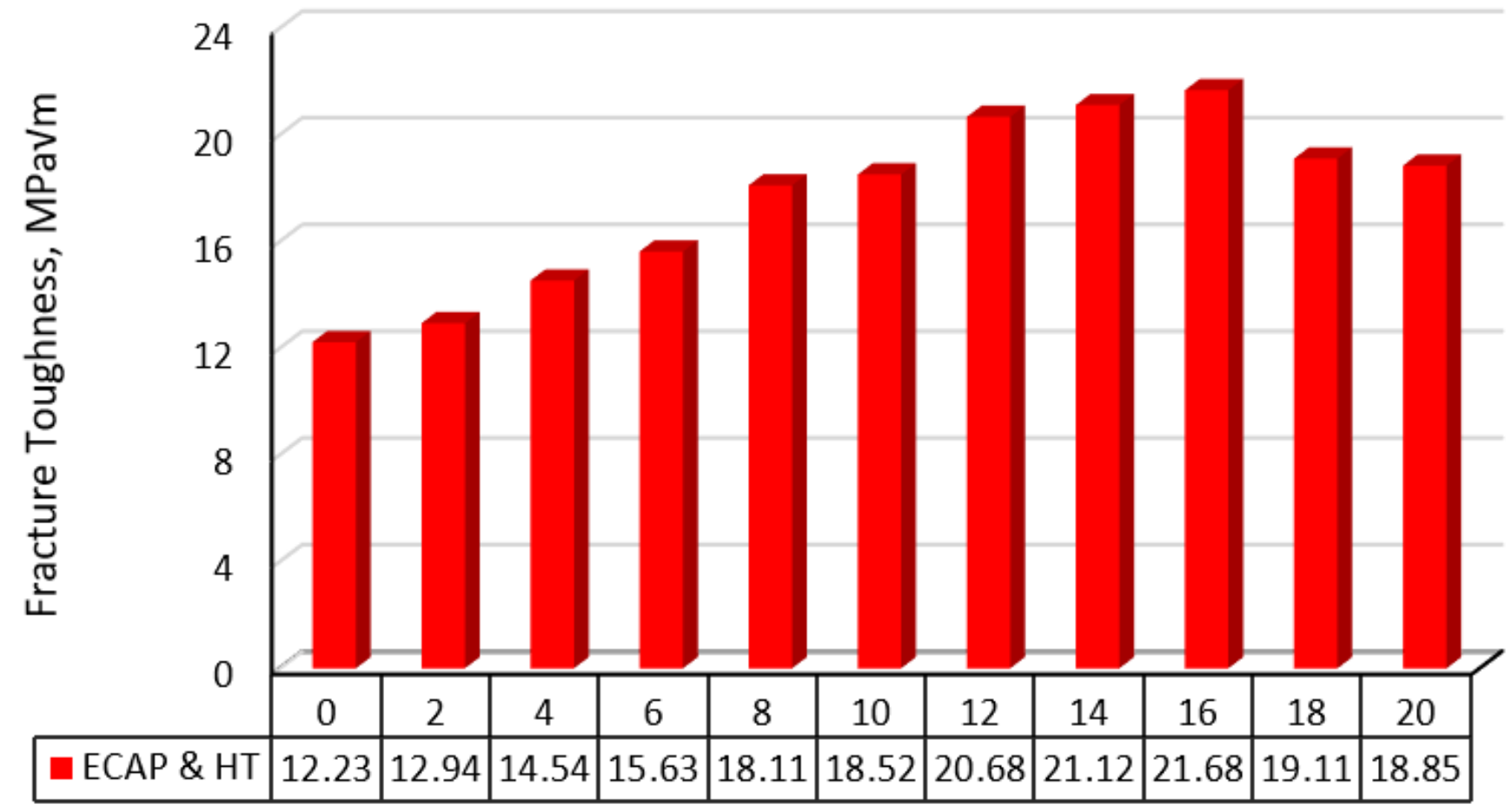

Aging Duration in Hrs

Figure 7

Variations of Fracture Toughness for different aging conditions after ECAP 


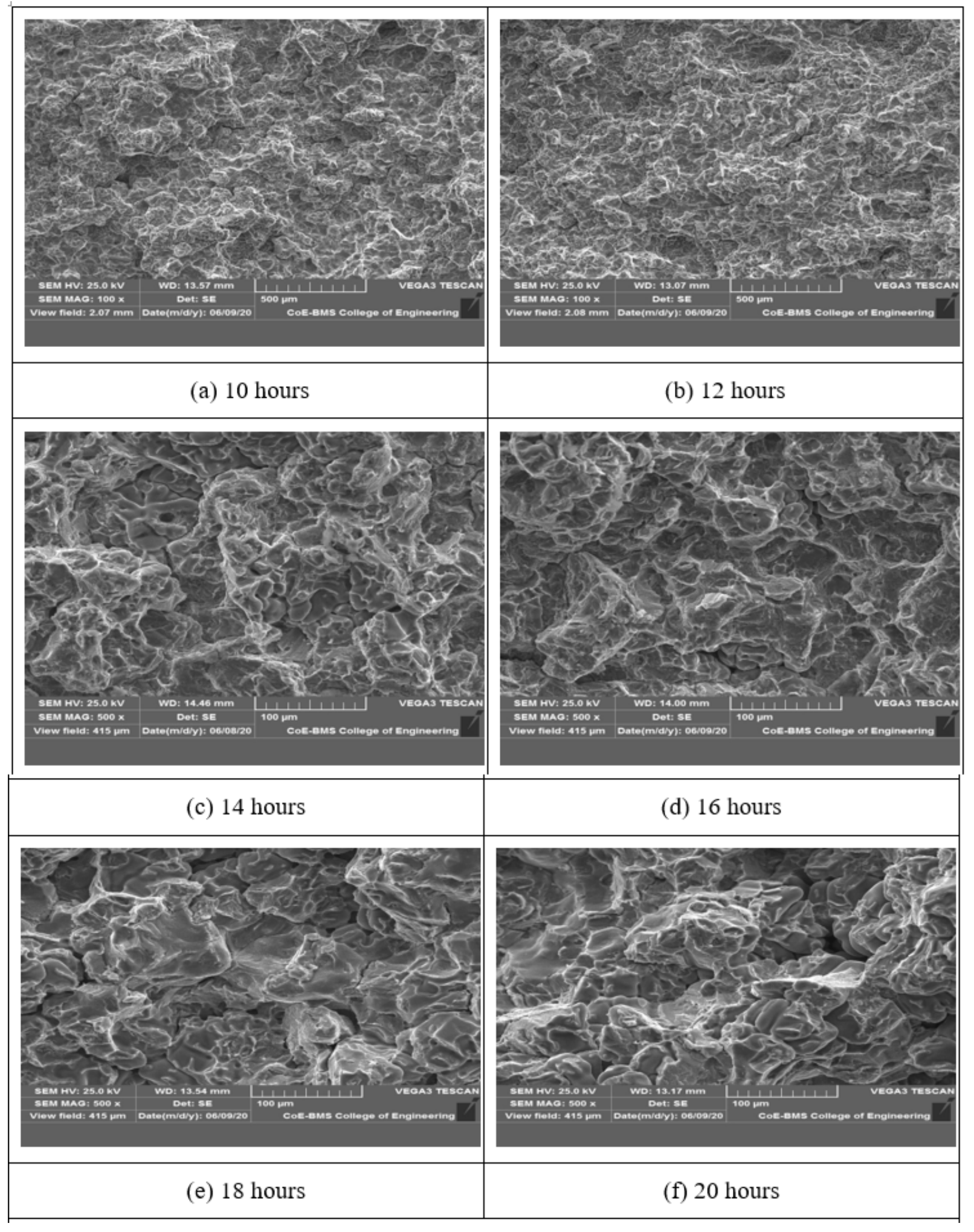

\section{Figure 8}

SEM fracture surfaces of Al-Zn alloy for different ageing temperatures taken after Fracture toughness test 